\title{
Does intensive insulin therapy really reduce mortality in critically ill surgical patients? A reanalysis of meta-analytic data
}

\author{
Jan O Friedrich ${ }^{1,2,3 *}$, Clarence Chant ${ }^{4}$ and Neill KJ Adhikari ${ }^{1,5}$
}

\begin{abstract}
Two recent systematic reviews evaluating intensive insulin therapy (IIT) in critically ill patients grouped randomized controlled trials (RCTs) by type of intensive care unit (ICU). The more recent review found that IIT reduced mortality in patients admitted to a surgical ICU, but not in those admitted to medical ICUs or mixed medical-surgical ICUs, or in all patients combined. Our objective was to determine whether IIT saves lives in critically ill surgical patients regardless of the type of ICU. Pooling mortality data from surgical and medical subgroups in mixed-ICU RCTs (16 trials) with RCTs conducted exclusively in surgical ICUs (five trials) and in medical ICUs (five trials), respectively, showed no effect of IIT in the subgroups of surgical patients (risk ratio $=0.85,95 \%$ confidence interval $(\mathrm{Cl})$ $=0.69$ to $1.04, P=0.11 ; P=51 \%, 95 \% \mathrm{Cl}=1$ to $75 \%)$ or of medical patients (risk ratio $=1.02,95 \% \mathrm{Cl}=0.95$ to $1.09, P=0.61 ; P=0 \%, 95 \% \mathrm{Cl}=0$ to $41 \%)$. There was no differential effect between subgroups (interaction $P=0.10$ ). There was statistical heterogeneity in the surgical subgroup, with some trials demonstrating significant benefit and others demonstrating significant harm, but no surgical subgroup consistently benefited from IIT. Such a reanalysis suggests that IIT does not reduce mortality in critically ill surgical patients or medical patients. Further insights may come from individual patient data meta-analyses or from future large multicenter RCTs in more narrowly defined subgroups of surgical patients.
\end{abstract}

*Correspondence: j.friedrich@utoronto.ca

${ }^{2}$ Critical Care and Medicine Departments, St Michael's Hospital, 30 Bond Street, Bond Wing, Room 4-015 Bond, Toronto, Ontario, Canada M5B 1W8

Full list of author information is available at the end of the article

\section{Introduction}

Two recent systematic reviews that evaluated intensive insulin therapy (IIT) in critically ill patients grouped the included randomized controlled trials (RCTs) by type of intensive care unit (ICU): surgical versus medical versus mixed medical-surgical [1,2]. Both reviews found no mortality reduction among all critically ill patients. The more recent review by Griesdale and colleagues, however, found that IIT reduced mortality in patients admitted to surgical ICUs, but not in patients admitted to medical ICUs or mixed medical-surgical ICUs [2]. Potential explanations to support the beneficial effects of IIT among critically ill surgical patients were proposed in the accompanying editorial: a greater use of central and arterial lines in surgical ICUs, which allows for more accurate monitoring and correction of blood glucose; acute hyperglycemia in surgical patients, who are more likely to benefit from correction than medical patients with chronic elevations and adaptive responses; and better achievement of target glucose levels in surgical ICU studies compared with medical ICU or mixed ICU studies [3]. In contrast to the finding of the most recent review, however, the large NICE-SUGAR RCT enrolling over 6,000 critically ill patients suggested increased mortality both overall and among the subgroup of surgical patients [4]. (This largest trial to date was included in the most recent review but was analyzed among the mixed medical-surgical ICU group of trials [2].)

These contrasting results between the meta-analyses $[1,2]$ and the most recent trial [4] may stem from sensitivity of the meta-analytic results to methodologic decisions. In particular, the decision to group trials by type of ICU rather than by type of patient may not be intuitive for clinicians, for whom the important question is whether IIT saves lives in critically ill surgical patients regardless of the type of ICU in which they are treated, which depends on hospital organization. The objective of the present viewpoint article was therefore to determine whether IIT has a differential effect in surgical compared with medical critically ill patients by incorporating all available 
outcomes data from surgical and medical subgroups in mixed ICU trials.

\section{Categorizing surgical and medical subgroups by type of patient rather than type of ICU}

We considered all trials of IIT included in the two recent systematic reviews [1,2]. Our primary analysis used the RCTs included in the more recent review [2], which found differential effects between patients admitted to medical ICUs and surgical ICUs. The review's primary outcome was 90-day mortality - or, if not available, then hospital mortality, 28-day mortality, or ICU mortality (in descending order of preference; two trials reported only 6-month mortality). Since both reviews were published recently, we did not update the literature search; for included conference abstracts, however, we searched for and used data from subsequently published full reports. For trials conducted in mixed ICUs, we extracted mortality data separately for surgical and medical subgroups, and contacted authors to request subgroup data when not reported in the original publication. We grouped these outcomes with data reported in trials conducted exclusively in surgical ICUs and in medical ICUs. We used the categorization of surgical patients and medical patients by the authors of the mixed ICU RCTs and assumed that trials conducted in surgical ICUs and medical ICUs included exclusively surgical patients and medical patients, respectively. For one RCT, classified differently in the two systematic reviews [1,2], we confirmed with the study authors that the trial was conducted in a mixed ICU [5]. For our primary analysis, we constructed a surgical subgroup including trial-level data from the surgical ICU trials and surgical group-level data from the mixed ICU trials. We used a similar approach for the medical subgroup.

Mortality data in each subgroup were pooled using random-effects models, which incorporate betweenstudy heterogeneity (Review Manager; Cochrane Collaboration, Oxford, UK), expressed as risk ratios (RRs) with 95\% confidence intervals (CIs). Pooled RRs in the surgical and medical subgroups were compared using a $z$ test, with a significance level of 0.05 . Statistical between-trial heterogeneity within each subgroup was assessed using the $I^{2}$ measure with $95 \%$ CIs [6].

We conducted three sensitivity analyses. The first included only trials conducted in mixed ICUs that enrolled both surgical patients and medical patients. This analysis addresses the possibility that differences between trials other than patient population could explain differential effects. The second analysis included trials in the first systematic review by Wiener and colleagues [1] that were excluded by the more recent review by Griesdale and colleagues [2]. The third analysis included only trials that actually achieved tight glucose control, as defined by a mean blood glucose of 4.4 to $6.1 \mathrm{mM}$ (the most commonly targeted range) in the intervention group.

Of the 16 RCTs conducted in mixed ICUs [4,5,7-20], mortality data for surgical and medical subgroups were available for 14 RCTs [4,5,7-18] and were unavailable for one RCT [19] after author contact; we were unable to contact the authors of one study [20]. These 14 RCTs provided data for 9,935/10,206 (97\%) of patients randomized in mixed ICU trials [4,5,7-18]. These data were combined with the five RCTs (1,972 patients) conducted exclusively in surgical ICUs [21-25] and the five RCTs (1,371 patients) in medical ICUs [26-30] included in the most recent review. For each included trial, Table 1 presents the target and mean achieved blood glucose values for both treatment groups and the mortality time point analyzed.

Meta-analyses showed no effect of IIT in the subgroups of surgical patients $(\mathrm{RR}=0.85,95 \% \mathrm{CI}=0.69$ to 1.04 , $P=0.11)$ or of medical patients $(\mathrm{RR}=1.02,95 \% \mathrm{CI}=0.95$ to $1.09, P=0.61$ ) (Figure 1 and Table 2). There was no evidence of a differential effect between subgroups $(P=0.10)$. There was moderate statistical heterogeneity in the surgical subgroup $\left(I^{2}=51 \%, 95 \% \mathrm{CI}=1\right.$ to $\left.75 \%\right)$ but none in the medical subgroup $\left(I^{2}=0 \%, 95 \% \mathrm{CI}=0\right.$ to $41 \%)$. Considering surgical patients, the effect of IIT appeared consistent in the subgroup of surgical ICU trials, in which the point estimate for $I^{2}$ is $0 \%$. However, the $95 \%$ confidence interval of this estimate of heterogeneity ( 0 to $70 \%$ ) is wide and similar to the $I^{2}$ confidence interval for both the surgical subgroup of the mixed ICU studies and the entire surgical patient population (see Figure 1a). This suggests that substantial heterogeneity cannot be excluded [31], even in the subgroup of surgical ICU trials.

Results of sensitivity analyses were similar to those of the primary analysis (Table 2). First, the analysis restricted to 12 mixed ICU trials enrolling both surgical and medical patients found $\mathrm{RR}=0.98(95 \% \mathrm{CI}=0.80$ to 1.19 , $\left.P=0.82 ; I^{2}=40 \%\right)$ in surgical patients and $\mathrm{RR}=1.03(95 \%$ $\mathrm{CI}=0.94$ to $\left.1.13, P=0.51 ; I^{2}=8 \%\right)$ in medical patients ( $P=0.66$ for comparison of RRs). Second, the analysis adding the results of the three surgical ICU trials [32-34] and the three medical ICU trials [35-37] included only in the earlier systematic review [1] found $\mathrm{RR}=0.89(95 \% \mathrm{CI}=$ 0.74 to $\left.1.08, P=0.24 ; I^{2}=45 \%\right)$ in surgical patients and $\mathrm{RR}=1.02\left(95 \% \mathrm{CI}=0.96\right.$ to $\left.1.09, P=0.46 ; I^{2}=0 \%\right)$ in medical patients $(P=0.18$ for comparison of RRs). Finally, the analysis of trials achieving tight glucose control (four out of eight surgical ICU trials, two out of eight medical ICU trials, and five out of 14 mixed ICU trials) found $\mathrm{RR}=0.76$ (95\% $\mathrm{CI}=0.57$ to $1.01, P=0.06$; $\left.I^{2}=10 \%\right)$ in surgical patients and $\mathrm{RR}=1.04(95 \% \mathrm{CI}=$ 0.71 to $\left.1.53, P=0.82 ; I^{2}=7 \%\right)$ in medical patients $(P=0.20$ for comparison of RRs). This last subgroup 
Table 1. Target and achieved blood glucose and mortality outcome time point by trial

\begin{tabular}{|c|c|c|c|c|c|}
\hline \multirow[b]{2}{*}{ Study } & \multicolumn{2}{|c|}{ Intervention group } & \multicolumn{2}{|c|}{ Control group } & \multirow[b]{2}{*}{$\begin{array}{c}\text { Mortality } \\
\text { outcome } \\
\text { time point }\end{array}$} \\
\hline & $\begin{array}{c}\text { Glucose } \\
\text { target } \\
\text { (mM) }\end{array}$ & $\begin{array}{l}\text { Mean achieved } \\
\text { glucose } \\
\text { (mM) }\end{array}$ & $\begin{array}{c}\text { Glucose } \\
\text { target } \\
\text { (mM) }\end{array}$ & $\begin{array}{l}\text { Mean achieved } \\
\text { glucose } \\
\text { (mM) }\end{array}$ & \\
\hline \multicolumn{6}{|c|}{ Studies included in the more recent systematic review [2] } \\
\hline \multicolumn{6}{|l|}{ Surgical ICU studies } \\
\hline Van den Berghe and colleagues [21] & 4.4 to 6.1 & 5.7 & 10.0 to 11.1 & 8.5 & Hospital \\
\hline Grey and Perdrizet [22] & 4.4 to 6.7 & 6.9 & 10.0 to 12.2 & 9.9 & Hospital \\
\hline Bilotta and colleagues (SAH) [23] & 4.4 to 6.7 & 5.0 & $<12.2$ & 8.3 & 6-month \\
\hline He and colleagues [24] & 4.4 to 8.3 & 6.7 & 10.0 to 11.1 & 10.0 & Hospital \\
\hline Bilotta and colleagues (TBI) [25] & 4.4 to 6.7 & 5.1 & $<12.2$ & 8.2 & 6-month \\
\hline \multicolumn{6}{|l|}{ Medical ICU studies } \\
\hline Bland and colleagues [26] & 4.4 to 6.1 & 5.8 & 10.0 to 11.1 & 9.8 & 28-day \\
\hline Van den Berghe and colleagues [27] & 4.4 to 6.1 & 6.2 & 10.0 to 11.1 & 8.5 & 90-day \\
\hline Walters and colleagues [28] & 5.0 to 8.0 & 6.9 & $\leq 15.0$ & 8.1 & 30-day \\
\hline Oksanen and colleagues [29] & 4.0 to 6.0 & 5.0 & 6.0 to 8.0 & 6.4 & 30-day \\
\hline Bruno and colleagues [30] & 5.0 to 7.2 & 7.4 & $<11.1$ & 10.6 & 90-day \\
\hline \multicolumn{6}{|l|}{ Mixed medical-surgical ICU studies } \\
\hline Mitchell and colleagues [8] & 4.4 to 6.1 & 5.4 & 10.0 to 11.1 & 7.9 & Hospital \\
\hline Azevedo and colleagues [9] & 4.4 to 6.7 & 7.4 & $<10.0$ & 8.0 & ICU \\
\hline Preiser and colleagues [11] & 4.4 to 6.1 & 6.6 & 7.8 to 10.0 & 8.2 & Hospital \\
\hline Brunkhorst and colleagues [12] & 4.4 to 6.1 & 6.2 & 10.0 to 11.1 & 8.4 & 90-day \\
\hline lapichino and colleagues [13] & 4.4 to 6.1 & 6.1 & 10.0 to 11.1 & 9.1 & 90-day \\
\hline He and colleagues [14] & 4.4 to 6.1 & 5.1 & 10.0 to 11.1 & 10.6 & ICU \\
\hline Zhang and colleagues [15] & 4.4 to 6.1 & 6.1 & 10.0 to 11.1 & 7.7 & Hospital \\
\hline De La Rosa and colleagues [16] & 4.4 to 6.1 & 6.5 & 10.0 to 11.1 & 8.2 & Hospital \\
\hline Arabi and colleagues [17] & 4.4 to 6.1 & 6.4 & 10.0 to 11.1 & 9.5 & Hospital \\
\hline Mackenzie and colleagues [18] & 4.0 to 6.0 & 7.0 & $<11.0$ & 8.4 & Hospital \\
\hline NICE-SUGAR [4] & 4.5 to 6.0 & 6.4 & $<10.0$ & 8.0 & 90-day \\
\hline Farah and colleagues [5] & 6.1 to 7.8 & 7.9 & 7.8 to 11.1 & 9.7 & 28-day \\
\hline Yu and colleagues [7] & 4.4 to 6.1 & 5.7 & 10.0 to 11.1 & 11.1 & Hospital \\
\hline McMullin and colleagues [10] & 5.0 to 7.0 & 7.1 & 8.0 to 10.0 & 9.4 & Hospital \\
\hline \multicolumn{6}{|c|}{ Additional studies included only in the earlier systematic review [1] } \\
\hline \multicolumn{6}{|c|}{ Surgical ICU studies } \\
\hline Stecher and colleagues [32] & 4.4 to 6.1 & $\mathrm{n} / \mathrm{a}$ & 7.8 to 10.0 & $\mathrm{n} / \mathrm{a}$ & $\mathrm{n} / \mathrm{a}$ \\
\hline Kia and colleagues [33] & 4.2 to 6.4 & 6.0 & 10.0 to 11.1 & 8.0 & 90-day \\
\hline Chan and colleagues [34] & 4.4 to 6.7 & 7.0 & $<11.1$ & 9.3 & Hospital \\
\hline \multicolumn{6}{|l|}{ Medical ICU studies } \\
\hline Fernandez and colleagues [35] & 4.4 to 6.1 & 6.7 & $<8.3$ & 11.4 & Hospital \\
\hline Davies and colleagues [36] & 4.0 to 8.0 & 10.3 & $<10.0$ & 10.7 & Hospital \\
\hline Gray and colleagues [37] & 4.0 to 7.0 & 6.3 & $<17.0$ & 6.8 & 90-day \\
\hline
\end{tabular}

ICU, intensive care unit; $n / a$, not available; $S A H$, subarachnoid hemorrhage; $T B I$, traumatic brain injury.

analysis is dominated by the largest surgical ICU trial [21] and excludes the six other largest trials (one in a medical ICU [27] and five in mixed ICUs [4,11,12,16,17]) that targeted the same blood glucose range in the intervention group (4.4 to $6.1 \mathrm{mM}$ ) but achieved slightly higher mean values (6.2 to $6.6 \mathrm{mM})$. Although there was a nonsignificant trend to benefit of IIT in the surgical subgroup considered in isolation for this sensitivity analysis, there is no evidence that the effect differed from medical patients.

Given this lack of difference between surgical and medical subgroups in any of the primary or secondary 


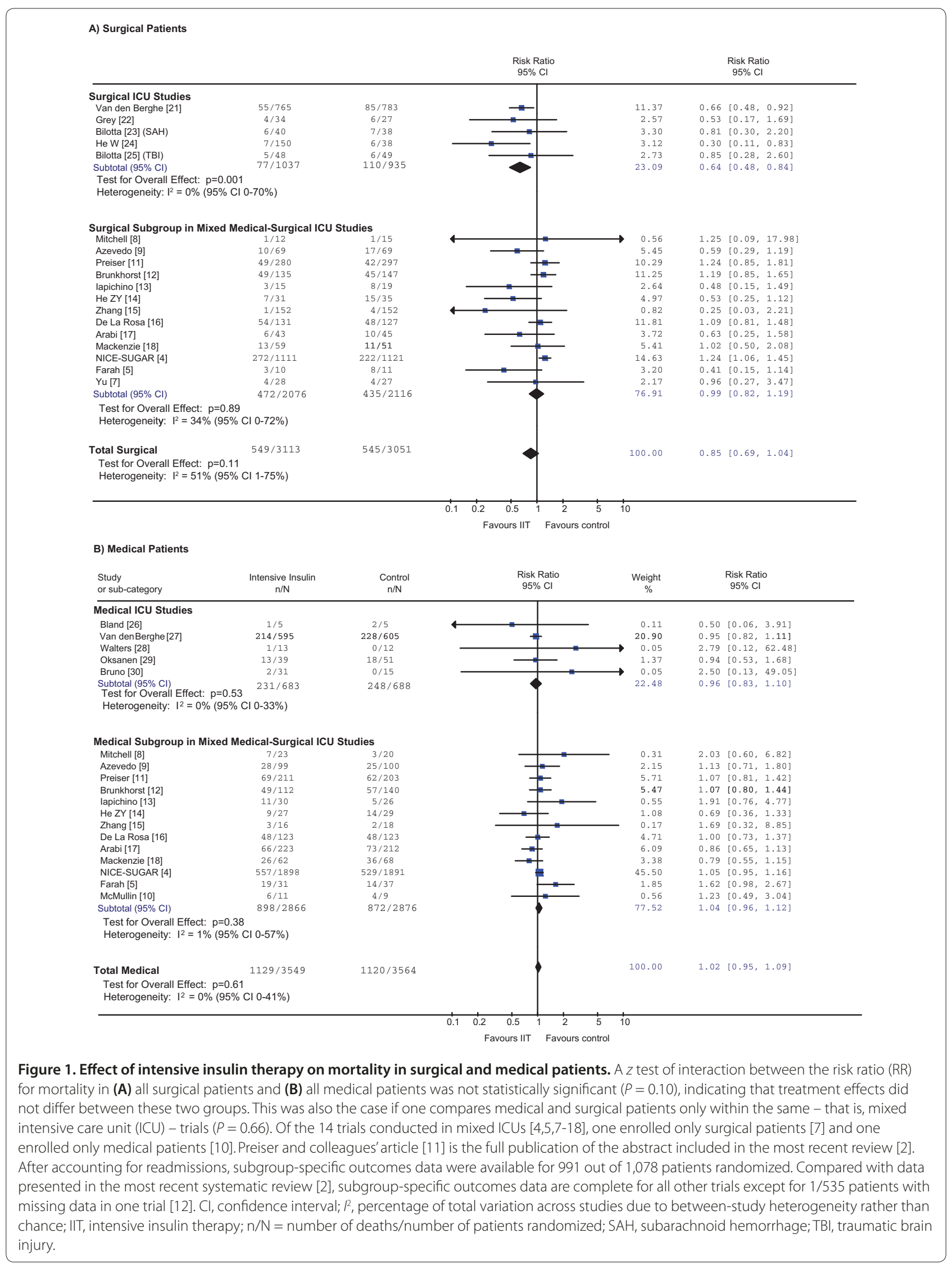


Table 2. Summary of pooled results of primary and sensitivity analyses

\begin{tabular}{|c|c|c|c|c|}
\hline \multirow[b]{2}{*}{ Analysis } & \multicolumn{3}{|c|}{ Pooled results } & \multirow[b]{2}{*}{$P$ value ${ }^{b}$} \\
\hline & All trials ${ }^{\mathrm{a}}$ & Surgical patient subgroup & Medical patient subgroup & \\
\hline \multicolumn{5}{|l|}{ Primary } \\
\hline $\begin{array}{l}\text { Trials included in more } \\
\text { recent review [2]c }\end{array}$ & $\begin{array}{c}0.93(0.84 \text { to } 1.04, P=0.20) \\
P=45 \%(2 \text { to } 69 \%) ; \\
26 \text { trials; } 13,549 \text { patients }\end{array}$ & $\begin{array}{c}0.85(0.69 \text { to } 1.04, P=0.11) \\
R^{2}=51 \%(1 \text { to } 75 \%) \\
18 \text { trials; } 6,164 \text { patients }\end{array}$ & $\begin{array}{c}1.02(0.95 \text { to } 1.09, P=0.61) \\
P=0 \%(0 \text { to } 41 \%) ; \\
18 \text { trials; } 7,113 \text { patients }\end{array}$ & 0.10 \\
\hline \multicolumn{5}{|l|}{ Sensitivity } \\
\hline $\begin{array}{l}\text { Only mixed ICU trials } \\
\text { enrolling both surgical } \\
\text { and medical patients }\end{array}$ & $\begin{array}{c}0.97(0.85 \text { to } 1.11, P=0.66) \\
R^{2}=54 \%(0 \text { to } 79 \%) \\
14 \text { trials; } 10,121 \text { patients }\end{array}$ & $\begin{array}{c}0.98(0.80 \text { to } 1.19, P=0.82) \\
R^{2}=40 \%(0 \text { to } 75 \%) \\
12 \text { trials; } 4,137 \text { patients }\end{array}$ & $\begin{array}{c}1.03(0.94 \text { to } 1.13, P=0.51) \\
R=8 \%(0 \text { to } 62 \%) ; \\
12 \text { trials; } 5,722 \text { patients }\end{array}$ & 0.66 \\
\hline $\begin{array}{l}\text { Incorporating additional } \\
\text { trials included in earlier } \\
\text { review [1] }\end{array}$ & $\begin{array}{c}0.96(0.87 \text { to } 1.06, P=0.43) \\
P^{2}=36 \%(0 \text { to } 61 \%) \\
32 \text { trials; } 15,051 \text { patients }\end{array}$ & $\begin{array}{c}0.89(0.74 \text { to } 1.08, P=0.24) \\
P^{2}=45 \%(0 \text { to } 71 \%) \\
21 \text { trials; } 6,644 \text { patients }\end{array}$ & $\begin{array}{c}1.02(0.96 \text { to } 1.09, P=0.46), \\
R=0 \%(0 \text { to } 31 \%) \\
21 \text { trials; } 8,135 \text { patients }\end{array}$ & 0.18 \\
\hline $\begin{array}{l}\text { Only trials achieving } \\
\text { mean blood glucose } \\
4.4 \text { to } 6.1 \mathrm{mM} \text { in IIT group }\end{array}$ & $\begin{array}{c}0.80(0.60 \text { to } 1.07, P=0.14) \\
R=43 \%(0 \text { to } 76 \%) \\
12 \text { trials; } 2,879 \text { patients }\end{array}$ & $\begin{array}{c}0.76(0.57 \text { to } 1.01, P=0.06) \\
R=10 \%(0 \text { to } 68 \%) \\
9 \text { trials; } 2,474 \text { patients }\end{array}$ & $\begin{array}{c}1.04(0.71 \text { to } 1.53, P=0.82) \\
R=7 \%(0 \text { to } 76 \%) ; \\
6 \text { trials; } 289 \text { patients }\end{array}$ & 0.20 \\
\hline
\end{tabular}

Data presented as risk ratio ( $95 \%$ confidence interval). $P^{2}$, percentage of total variation across studies due to between-study heterogeneity rather than chance; ICU, intensive care unit; IIT, intensive insulin therapy. Includes also mixed ICU trials for which separate surgical and medical subgroup data were not available [19,20]. bSurgical versus medical interaction. 'See also Figure 1.

analyses, the best estimate of IIT effect in both subgroups is the overall effect, which is nil (see Table 2).

\section{Discussion and conclusions}

Our analysis shows no effect of IIT in surgical or medical critically ill patients. We found moderate between-trial differences in the effect of IIT in the surgical subgroup, reflecting the contrasting results of two trials enrolling the most surgical patients: the study by Van den Berghe and colleagues [21] and the NICE-SUGAR study [4]. As noted by other studies $[1,2,21,38,39]$, multiple factors may have contributed to the positive result in the singlecenter trial by Van den Berghe and colleagues that mainly enrolled cardiac surgery patients [21]: patient population (higher control group mortality than expected), local care practices (in particular, routine use of intravenous glucose and parenteral nutrition [40]), early stopping after an interim analysis showed benefit, and a higher target glucose range in the control group compared with other trials.

Furthermore, our analysis reveals the variable definitions of surgical patients that may also have contributed to between-trial heterogeneity: some trials included only postoperative patients, while others also included patients who required ICU readmission from surgical wards or nonoperative patients with surgical diagnoses such as pancreatitis or trauma. Based on the available data, there does not appear to be any obvious subgroup of surgical patients that consistently benefits from IIT. Of the two trials conducted in patients after cardiac surgery, Van den Berghe and colleagues found a mortality benefit [21], but the much smaller trial by Chan and colleagues did not [34]. Moreover, Van den Berghe and colleagues' trial included patients who required ICU readmission from surgical wards in addition to immediately postoperative patients. Other trials classified such patients as medical, and no trial suggested benefit in medical patients. Furthermore, in the NICE-SUGAR trial, operative patients were defined as immediately postoperative ICU admissions - and this trial actually suggested harm in such patients [4].

In summary, we analyzed the effect of IIT in surgical patients, regardless of the type of ICU to which they were admitted, and found no effect on mortality - similar to the effect for critically ill medical patients and all critically ill patients combined $[1,2]$. We therefore do not recommend this intervention for critically ill surgical patients or critically ill medical patients. Further insights into the effects of this intervention in surgical patients may come from individual patient data meta-analyses, acknowledging the challenges of ensuring availability and comparability of data among trials and obtaining expert statistical support. Alternatively, future large multicenter RCTs in specific patient subgroups, such as cardiac surgical patients, may further refine our understanding of the role of IIT in the ICU.

\section{Abbreviations}

$\mathrm{Cl}$, confidence interval; $P$, percentage of total variation across studies due to between-study heterogeneity rather than chance; ICU, intensive care unit; IT, intensive insulin therapy; RCT, randomized controlled trial; RR, risk ratio.

\section{Competing interests}

The authors declare that they have no competing interests.

\section{Acknowledgements}

The authors would like to thank the following authors for kindly providing surgical and medical subgroup mortality data for their trials: Yaseen Arabi [17]; José Raimundo Azevedo [9]; Frank Brunkhorst and Evelyn Kuhnt [12]; Gisela De La Rosa [16]; Wei He [15]; Zhenyang He [14]; Gaetano lapichino, Frederico Polli, and Luciano Gattinoni [13]; lain Mackenzie [18]; Imogen Mitchell, Elise Crowfoot and Rebecca Ashley [8]; Jean-Charles Preiser and Christian Mélot 
[11]; Alex Samokhvalov [5]; and Wenkui Yu [7]. The present study received no specific funding. JOF is supported by a Canadian Institutes of Health Research Clinician Scientist Award. The Canadian Institutes of Health Research had no involvement in the conduct of this study.

\section{Author details}

IInterdepartmental Division of Critical Care and Department of Medicine, University of Toronto, R. Fraser Elliot Building, 3rd Floor, South Wing, 3S-805, 190 Elizabeth Street, Toronto, Ontario, Canada M5G 2C4. ${ }^{2}$ Critical Care and Medicine Departments, St Michael's Hospital, 30 Bond Street, Bond Wing Room 4-015 Bond, Toronto, Ontario, Canada M5B 1W8. 'Keenan Research Centre, Li Ka Shing Knowledge Institute, St Michael's Hospital, 30 Bond Street, Toronto, Ontario, Canada M5B 1W8. ${ }^{4}$ Department of Pharmacy, St Michael's Hospital, 30 Bond Street, Queen Wing, Room Q4036, Toronto, Ontario, Canada M5B 1W8. ${ }^{5}$ Department of Critical Care Medicine and Sunnybrook Research Institute, Sunnybrook Health Sciences Centre, 2075 Bayview Avenue, Toronto, Ontario, Canada M4N 3M5

Published: 21 October 2010

\section{References}

1. Wiener RS, Wiener DC, Larson RJ: Benefits and risks of tight glucose control in critically ill adults: a meta-analysis. JAMA 2008, 300:933-944.

2. Griesdale DEG, de Souza RJ, van Dam RM, Heyland DK, Cook DJ, Malhotra A, Dhaliwal R, Henderson WR, Chittock DR, Finder S, Talmor D: Intensive insulin therapy and mortality among critically ill patients: a meta-analysis including NICE-SUGAR study data. CMAJ 2009, 180:821-827.

3. Van den Berghe $G$, Mesotten $D$, Vanhorebeek I: Intensive insulin therapy in the intensive care unit. CMAJ 2009, 180:799-800.

4. NICE-SUGAR Study Investigators: Intensive versus conventional glucose control in critically ill patients. N Engl J Med 2009, 360:1283-1297.

5. Farah R, Samokhvalov A, Zviebel F, Makhoul N: Insulin therapy of hyperglycemia in intensive care. Isr Med Assoc J 2007, 9:140-142.

6. Higgins JPT, Thompson SG: Quantifying heterogeneity in a meta-analysis. Stat Med 2002, 21:1539-1558.

7. Yu WK, Li WQ, Wang XD, Yan XW, Qi XP, Li N, Li JS: Influence and mechanism of a tight control of blood glucose by intensive insulin therapy on human sepsis [in Chinese]. Zhonghua Wai Ke Za Zhi 2006, 43:29-32.

8. Mitchell I, Knight E, Gissane J, Tamhane R, Kolli R, Leditschke IA, Bellomo R, Finder S: Australian and New Zealand Intensive Care Society Trials Group: A phase II randomized controlled trial of intensive insulin therapy in general intensive care patients. Crit Care Resusc 2006, 8:289-293.

9. Azevedo JRA, de Araujo LO, da Silva WS, de Azevado RP: A carbohydraterestrictive strategy is safer and as efficient as intensive insulin therapy in critically ill patients. J Crit Care 2010, 25:84-89.

10. McMullin J, Brozek J, McDonald E, Clarke F, Jaeschke R, Heels-Ansdell D, Leppert R, Foss A, Cook D: Lowering of glucose in critical care: a randomized pilot trial. J Crit Care 2007, 22:112-118

11. Preiser J-C, Devos P, Ruiz-Santana S, Mélot C, Annane D, Groeneveld J, lapichino G, Leverve X, Nitenberg G, Singer P, Wernerman J, Joannidis M, Stecher A, Chioléro R: A prospective randomised multi-centre controlled trial on tight glucose control by intensive insulin therapy in adult intensive care units: the glucontrol study. Intensive Care Med 2009, 35:1738-1748.

12. Brunkhorst FM, Engel C, Bloos F, Meier-Hellmann A, Ragaller M, Weiler N, Moerer O, Gruendling M, Oppert M, Grond S, Olthoff D, Jaschinski U, John S, Rossaint R, Welte T, Schaefer M, Kern P, Kuhnt E, Kiehntopf M, Hartog C, Natanson C, Loeffler M, Reinhart K: German Competence Network Sepsis: Intensive insulin therapy and pentastarch resuscitation in severe sepsis. NEngl J Med 2008, 358:125-139.

13. lapichino G, Albicini M, Umbrello M, Sacconi F, Fermo I, Pavlovich R, Paroni R, Bellani G, Mistraletti G, Cugno M, Pesenti A, Gattinoni L: Tight glycemic control does not affect asymmetric-dimethylarginine in septic patients. Intensive Care Med 2008, 34:1843-1850

14. He ZY, Li N, Xing J, Xie HA, Wu Y: Effect of intensive insulin therapy on shortterm outcome in critically ill patients [in Chinese]. Chinese J Clin Nutr 2008, 16:220-222.

15. Zhang RL, He W, LiT, Zhou H, Wang C, Gao S, Xu Y: Evaluation of optimal goal of glucose control in critically ill patients [in Chinese]. Chinese J Clin Nutr 2008, 16:204-208

16. De La Rosa Gdel C, Donado JH, Restrepo AH, Quintero AM, Gonzalez LG,
Saldarriaga NE, Bedoya M, Toro JM, Velasquez JB, Valencia JC, Arango CM Aleman PH, Vasquez EM, Chavarriaga JC, Yepes A, Pulido W, Cadavid CA; Grupo de Investigacion en Cuidado intensivo: Strict glycaemic control in patients hospitalised in a mixed medical and surgical intensive care unit: a randomised clinical trial. Crit Care 2008, 12:R120.

17. Arabi YM, Dabbagh OC, Tamim HM, Al-Shimemeri AA, Memish ZA, Haddad SH, Syed SJ, Giridhar HR, Rishu AH, Al-Daker MO, Kahoul SH, Britts RJ, Sakkijha $\mathrm{MH}$ : Intensive versus conventional insulin therapy: a randomized controlled trial in medical and surgical critically ill patients. Crit Care Med 2008, 36:3190-3197.

18. Mackenzie IM, Ercole A, Ingle S, Palmer CR: Glycaemic control and outcome in general intensive care: the East Anglian GLYCOGENIC study. Br I Intensive Care 2008, 18:121-126.

19. Henderson WR, Dhingra V, Chittock D, Foster D, Hebert P, Cook C, Heyland D, Dodek P, Griesdale D, Schulzer M, Ronco Jj; Canadian Critical Care Trials Group: The efficacy and safety of glucose control algorithms in intensive care. A pilot study of the Survival Using Glucose Algorithm Regulation (SUGAR) trial. Pol Arch Med Wewn 2009, 119:439-446.

20. Wang LC, Lei S, Wu YC, Wu JN, Wang LF, Guan TR, Jiang HF, Ni HX, Ye XH: Intensive insulin therapy in critically ill patients [in Chinese]. Zhongguo Wei Zhong Bing Ji Jiu Yi Xue 2006, 18:748-750.

21. Van den Berghe G, Wouters P. Weekers F, Verwaest C, Bruyninckx F, Schetz M, Vlasselaers D, Ferdinande P, Lauwers P, Bouillon R: Intensive insulin therapy in critically ill patients. N Engl J Med 2001, 345:1359-1367.

22. Grey NJ, Perdrizet GA: Reduction of nosocomial infections in the surgical intensive-care unit by strict glycemic control. Endocr Pract 2004, 10:46-52.

23. Bilotta F, Spinelli A, Giovannini F, Doronzio A, Delfini R, Rosa G: The effect of intensive insulin therapy on infection rate, vasospasm, neurologic outcome, and mortality in neurointensive care unit after intracranial aneurysm clipping in patients with acute subarachnoid hemorrhage: a randomized prospective pilot trial. J Neurosurg Anesthesiol 2007, 19:156-160.

24. He W, Zhang TY, Zhou H, Li T, Zhao JY, Zhao D, Liu XH, Hou J, Wang C, Xu Y: Impact of intensive insulin therapy on surgical critically ill patients [in Chinese]. Zhonghua Wai Ke Za Zhi 2007, 45:1052-1054.

25. Bilotta F, Caramia R, Cernak I, Paoloni FP, Doronzio A, Cuzzone V, Santoro A, Rosa R: Intensive insulin therapy after severe traumatic brain injury: a randomized clinical trial. Neurocrit Care 2008, 9:159-166.

26. Bland DK, Fankhanel Y, Langford E, Lee M, Lee SW, Maloney C, Rogers M, Zimmerman G: Intensive versus modified conventional control of blood glucose level in medical intensive care patients: a pilot study. Am J Crit Care 2005, 14:370-376

27. Van den Berghe G, Wilmer A, Hermans G, Meersseman W, Wouters PJ, Milants I, Van Wijngaerden E, Bobbaers H, Bouillon R: Intensive insulin therapy in the medical ICU. N Engl J Med 2006, 354:449-461.

28. Walters MR, Weir CJ, Lees KR: A randomised, controlled pilot study to investigate the potential benefit of intervention with insulin in hyperglycaemic acute ischaemic stroke patients. Cerebrovasc Dis 2006 22:116-122.

29. Oksanen T, Skrifvars MB, Varpula T, Kuitunen A, Pettila V, Nurmi J, Castren M Strict versus moderate glucose control after resuscitation from ventricular fibrillation. Intensive Care Med 2007, 33:2093-2100.

30. Bruno A, Kent TA, Coull BM, Shankar RR, Saha C, Becker KJ, Kissela BM Williams LS: Treatment of hyperglycemia in ischemic stroke (THIS): a randomized pilot trial. Stroke 2008, 39:384-389

31. Ioannidis J, Patsopoulos N, Evangelou E: Uncertainty in heterogeneity estimates in meta-analysis. BMJ 2007, 135:914-916.

32. Stecher A, Steblaj S, Kermzar B, Invanova E: The influence of normoglycemia on ventilator-associated pneumonia in trauma patients. In Proceedings of European Trauma Congress; May 24-26 2006; Ljubljana, Slovenia.

33. Kia M, Botdorf J, Barber KR: The effects of strict glycemic control in the critically ill general and vascular surgical patient. In Proceedings of $91^{\text {st }}$ Annual Clinical Congress of the American College of Surgeons; October 16-20 2005; San Francisco, CA.

34. Chan RPC, Galas FRBG, Haijar LA, Bello CN, Piccioni MA, Auler Jr JOC: Intensive perioperative glucose control does not improve outcomes of patients submitted to open-heart surgery: a randomized controlled trial. Clinics (Sao Paolo) 2009, 64:51-60.

35. Fernandez R, Boque M, Galera A, Rodriquez-Cintron W: Insulin: effect on mortality and renal failure in medical intensive care unit patients [abstract]. Proc Am Thor Soc 2005, 2:A37.

36. Davies RR, Newton RW, McNeill GP, Fisher BM, Kesson CM, Pearson D: 
Metabolic control in diabetic subjects following myocardial infarction: difficulties in improving blood glucose levels by intravenous insulin infusion. Scott Med J 1991, 36:74-76.

37. Gray CS, Hildreth AJ, Sandercock PA, O'Connell JE, Johnston DE, Cartlidge NEF, Bamford JM, James OF, Alberti KGMM; GIST Trialists Collaboration: Glucosepotassium-insulin infusions in the management of post-stroke hyperglycaemia: the UK Glucose Insulin in Stroke Trial (GIST-UK). Lancet Neurol 2007, 6:397-406.

38. Angus DC, Abraham E: Intensive insulin therapy in critical illness. Am J Respir Crit Care Med 2005, 172:1358-1359.
39. Bellomo R, Egi M: Glycemic control in the intensive care unit: why we should wait for NICE-SUGAR. Mayo Clin Proc 2005, 80:1546-1548.

40. Marik PE, Preiser J-C: Towards understanding tight glycemic control in the ICU: a systematic review and meta-analysis. Chest 2010, 137:544-551.

doi:10.1186/cc9240

Cite this article as: Friedrich JO, et al.: Does intensive insulin therapy really reduce mortality in critically ill surgical patients? A reanalysis of meta-

analytic data Critical Care 2010, 14:324. 